\title{
Accuracy, utility and complications of continuous glucose monitoring system (CGMS) in pediatric patients with type 1 diabetes
}

\author{
Acurácia, utilidade e complicações da monitorização subcutânea contínua da glicose (CGMS) \\ em pacientes pediátricos com diabetes tipo 1
}

\section{Frederico F. R. Maia, ${ }^{1}$ Levimar R. Araújo $^{2}$}

\begin{abstract}
Objective: To evaluate the accuracy, utility and complications of continuous glucose monitoring system in children and adolescents with type 1 diabetes.

Methods: This retrospective study assessed 16 type 1 diabetic patients ( $16.12 \pm 4.41$ years) submitted to continuous glucose monitoring system (Medtronic; Northridge, CA) for 72 hours. The following parameters were analyzed: mean capillary glucose level and mean glucose value measured by the continuous glucose monitoring system; glucose excursions (continuous glucose monitoring system vs. capillary glucose measurement), postprandial hyperglycemia ( $N R<140 \mathrm{mg} / \mathrm{dl}$ ), nocturnal hypoglycemia, complications (trauma, local infection, disconnection) and therapeutic management after continuous glucose monitoring. A1c levels were measured at the beginning and after 3 months of the study.
\end{abstract}

Results: The mean capillary glucose values were $214.3 \pm 66.5 \mathrm{mg} / \mathrm{dl}$ vs. $207.6 \pm 54.6 \mathrm{mg} / \mathrm{dl}$ by continuous glucose monitoring system, with a significant correlation $(p=0.001)$. The correlation coefficient and mean absolute error were $0.86 \pm 0.21$ and $12.6 \%$ of the median, respectively. The continuous glucose monitoring system was significantly more efficient in detecting glucose excursion than fingerstick capillary blood sampling ( $p=0.04 ; W=74)$, and postprandial hyperglycemia was identified in $60 \%$ of type 1 diabetic patients with a median value of $157 \mathrm{mg} / \mathrm{dl}$ ( $<140 \mathrm{mg} / \mathrm{dl}$ ). Nocturnal hypoglycemia was detected in $46.7 \%$ of these patients. The evaluation of A1c levels in eight (50\%) patients before continuous glucose monitoring and after 3 months showed a significantly lower level of A1c in this population ( $8.18 \pm 1.5$ vs. $7.28 \pm 1.3 ; p=0.034$ ). The therapeutic management of type 1 diabetes was changed in $100 \%$ of patients. No complications were detected in $93.7 \%$ of patients.

Conclusions: The continuous glucose monitoring system showed to be a very safe, well-tolerated and highly accurate method, with a low complication rate. It is a good method to identify glucose excursion and postprandial hyperglycemia, and to improve metabolic changes in therapeutic strategies, with a significant impact on the A1c levels of pediatric diabetic patients. The efficacy of the continuous glucose monitoring system in detecting hypoglycemia is still unclear in the medical literature.

J Pediatr (Rio J). 2005;81(4):293-7: Continuous glucose monitoring system, type 1 diabetes, hypoglycemia, hyperglycemia.

\section{Resumo}

Objetivo: Avaliar a acurácia, utilidade e complicações da monitorização subcutânea contínua da glicemia em crianças e adolescentes com diabetes melito tipo 1 (DM1).

Métodos: Foram estudados retrospectivamente 16 pacientes $(16,12 \pm 4,41$ anos), submetidos à monitorização subcutânea contínua da glicemia (Medtronic; Northridge, CA, EUA) por 72 horas. Foram analisados os valores de glicemia capilar média e pelo sensor monitorização subcutânea contínua da glicemia; excursões glicêmicas (monitorização subcutânea contínua da glicemia versus. glicemia capilar); hiperglicemia pós-prandial ( $<140 \mathrm{mg} / \mathrm{dl}$ ); hipoglicemia noturna assintomática; complicações (trauma, infecção local, desconexão) e conduta terapêutica após a monitorização subcutânea contínua da glicemia. Os níveis de A1c foram determinados antes e 3 meses após a monitorização subcutânea contínua da glicemia.

Resultados: A glicemia capilar média durante a monitorização subcutânea contínua da glicemia foi de $214,3 \pm 66,5 \mathrm{mg} / \mathrm{dl}$ vs. $207,6 \pm 54,6$ detectada pelo sensor, com correlação significante $(p=0,001)$. 0

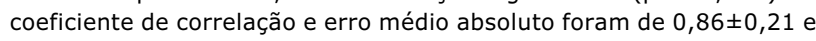
mediana de $12,6 \%$, respectivamente. A monitorização subcutânea contínua da glicemia mostrou-se mais eficaz na detecção de excursões glicêmicas $(p=0,04 ; W=74)$ em relação à glicemia capilar em ponta de dedo. A hiperglicemia pós-prandial foi identificada em $60 \%$ dos pacientes com DM1, com mediana de $157 \mathrm{mg} / \mathrm{dl}$ (< $140 \mathrm{mg} / \mathrm{dl}$ ). A hipoglicemia noturna assintomática foi detectada em $46,7 \%$ dos casos. A avaliação dos níveis de A1c em oito (50\%) pacientes, antes e após 3 meses da monitorização subcutânea contínua da glicemia, mostrou redução significante da $A 1 c(8,18 \pm 1,5$ vs. $7,28 \pm 1,3 ; p=0,034)$ nesse grupo de pacientes. A mudança de conduta terapêutica foi instituída em $100 \%$ das crianças e adolescentes. Não houve complicações durante o exame em $93,7 \%$ dos casos.

Conclusões: A monitorização subcutânea contínua da glicemia mostrou-se método seguro, bem tolerado, com alta acurácia nos valores glicêmicos detectados, com baixo índice de complicações. Esse método mostrou-se eficaz na deteç̧ão de excursões glicêmicas, hiperglicemia pós-prandial, na promoção de mudanças terapêuticas com redução importante da A1c em crianças e adolescentes diabéticos. A eficácia desse método na identificação da hipoglicemia assintomática ainda mostra-se indefinida na literatura.

J Pediatr (Rio J). 2005;81(4):293-7: Monitorização subcutânea contínua da glicemia, diabetes tipo 1, hipoglicemia, hiperglicemia.

1. Resident in Internal Medicine, Department of Internal Medicine, Hospital Universitário São José, Faculdade de Ciências Médicas de Minas Gerais (FCMMG), Belo Horizonte, MG.

2. General Coordinator of the Division of Endocrinology and Metabolism, Hospital Universitário São José, FCMMG, Belo Horizonte, MG.

Manuscript received Nov 16 2004, accepted for publication Mar 162005.

Suggested citation: Maia FF, Araújo LR. Accuracy, utility and complications of continuous glucose monitoring system (CGMS) in pediatric patients with type 1 diabetes. J Pediatr (Rio J). 2005;81:293-7. 


\section{Introduction}

Self-monitoring of blood glucose (SMBG) has become a major tool in the management of diabetes. ${ }^{1}$ The major inconvenience of SMBG is due to the fact that blood glucose is only intermittently measured by fingerstick capillary blood sampling, from which only a partial and therefore incomplete picture of blood glucose fluctuations can be made. 1,2 Because of many factors, including pain and inconvenience, many children with diabetes do not accept frequent fingersticks for SMBG. One parent of a child with diabetes compared his daughter's daily four SMBG values to hearing four notes of a symphony. ${ }^{3}$ The availability of the continuous glucose monitoring system (CGMS) (Medtronic; Northridge, CA, USA) offers the opportunity for pediatric type 1 diabetic patients to match the demands of intensive therapy with the intensive monitoring of blood glucose levels. ${ }^{1,2}$

The diabetes control and complications trial (DCCT) established that intensive and multidisciplinary treatment of type 1 diabetes mellitus (DM1) improves metabolic control and reduces the complications of the disease. 4 Estimates showed that a significant damage to quality of life is frequently due to DM1 in children and adolescents, including functional limitations, social and economic stress, even major depression. ${ }^{2}$ Psychological aspects and children's acceptance of DM1 may exercise some influence over their glucose control. 5

Despite excellent A1c levels and target preprandial glucose levels, pediatric diabetic patients often experience nocturnal hypoglycemia and postprandial hyperglycemia that are not evident with routine monitoring. ${ }^{6}$ In addition, families frequently do not measure blood glucose levels during the night and $55 \%$ of severe hypoglycemic events in the DCCT occurred during sleep. ${ }^{7}$ Several studies demonstrated the utility of the CGMS in improving metabolic control, detecting more glucose excursions (hypoglycemia and hyperglycemia) and in detecting more postprandial hyperglycemia than SMBG. ${ }^{8-12}$ The efficacy of the CGMS in detecting hypoglycemia is not well established in the medical literature. ${ }^{13-15}$

There was no information in Brazil about the effects of CGMS in pediatric type 1 diabetic patients. This study aimed to determine the impact of CGMS upon the detection of glucose excursions, unrecognized hypoglycemia and upon improving metabolic control in DM1 pediatric patients. The accuracy and complications of CGMS in children and adolescents are discussed.

\section{Subjects and methods Patients}

This retrospective study assessed 16 diabetic patients (16.12 \pm 4.41 years), whose duration of DM1 was 2-18 years, with a mean duration of $7.81 \pm 4.83$ years, submitted to CGMS for 72 hours (Medtronic; Northridge, CA, USA). Each child had a mean $\mathrm{HbA} 1 \mathrm{c}$ level > 7\% (range, 7-10.9\%) 3 months before participating in the study. All participants were on intensive insulin treatment, $20 \%$ receiving continuous subcutaneous insulin infusion (insulin pump therapy) and $80 \%$ receiving multiple daily injections (MDIs). There were $62.5 \%$ of females and $37.5 \%$ of males. The selection of these patients was based on the presence of DM1, HbA1c > 7\% 3 months before the exam and ability to operate the CGMS monitor. There were no restrictions regarding sex, race, education, social or economic status.

\section{Glucose sensor}

The Medtronic MiniMed (Northridge, CA, USA) CGMS, the first model approved by the FDA (Food and Drug Administration, USA) was used for subcutaneous glucose monitoring. Glucose is measured by an electrochemical assay of glucose oxidase, in which values from 40 to $400 \mathrm{mg} / \mathrm{dl}$ are detected. The system consists of a subcutaneous sensor connected by a cable to a pager-sized glucose monitor. Glucose readings are made by the monitor every 10 seconds and an average glucose value is stored in the monitor's memory every 5 minutes (up to 288 measurements per day and 864 in all exams). Each glucose sensor provides glucose information for up to 72 hours. After the initial 60 minutes, the electrical current in nanoampere is converted into glucose value after this information is measured by the monitor. The values stored in the monitor are downloaded by the MiniMed Com-Station and presented in graphical and statistical form via a computer program and the sensor is eliminated. The original Medtronic MiniMed glucose sensor was modified in November, 2002. This modification resulted in improved accuracy. In this study, the new modified sensors were utilized.

\section{Procedure}

All patients received basic instructions about the CGMS operation and about the registry of all events in the "patient's diary", by one of the authors (F.F.R.M). During the CGMS, all participants had to perform at least four capillary blood glucose (CBG) tests a day and enter these values into the CGMS monitor to obtain correlation coefficients between the SBGM and the CGMS values. All SBGM tests were performed using a digital glucometer (Accu-Chek Active; Roche Diagnosis). The first CBG value was entered after 60 minutes of CGMS. Families were asked not to change their dietary practices during the study.

The following parameters were analyzed: correlation coefficient (\%); mean absolute difference (MAD); number of sensor readings; duration of the exam (h); mean CBG and mean glucose value measured by the CGMS; glucose excursions (CGMS vs. CBG); postprandial hyperglycemia (normal range; NR < $140 \mathrm{mg} / \mathrm{dl}$ ); nocturnal hypoglycemia; A1c levels at the beginning and after 3 months; complications (trauma, local infection, disconnection), noncompliance, and therapeutic management after CGMS.

The correlation coefficient and MAD were calculated by the Medtronic software and defined as $>0.79 \%$ and $<28 \%$, respectively, to meet the optimal accuracy criteria. The MAD was determined by the average difference between the glucose values obtained by the sensor and blood glucose 
values in percentage (\%) for a given day. The number of measurements by the CGMS was considered significant if higher than $80 \%$ ( $>640$ readings/ $72 \mathrm{~h}$ ). The accuracy of the CGMS sensor was based on the comparison of capillary blood glucose values and the values obtained by the sensor using Pearson's correlation during hypoglycemia, normoglycemia and hyperglycemia, with a $\mathrm{p}$ value $<0.05$.

Symptomatic glucose excursions were based on patients' information and compared to the CGMS values. Hypoglycemia and hyperglycemia were defined as blood glucose $<70 \mathrm{mg} / \mathrm{dl}$ and $>180 \mathrm{mg} / \mathrm{dl}$, respectively. The duration of hypoglycemia, hyperglycemia and normoglycemia were recorded in percent for the sake of comparison. Postprandial hyperglycemia was considered when blood glucose values were over $140 \mathrm{mg} / \mathrm{dl} 2$ hours after lunch. Nocturnal hypoglycemia was detected by glucose $<70 \mathrm{mg} / \mathrm{dl}$ between 11 p.m. and 7 a.m.

A1c values were determined at the beginning and 3 months after the CGMS in 13 patients. A1c values were determined by using high performance liquid chromatography (HPLC), with a normal range of 4.3 to $6.9 \%$.

The complications during the CGMS were based on medical observation and patients' information. Complications were analyzed during the implantation of the sensor (bleeding and pain) and during the exam (trauma, local infection, disconnection, psychological aversion, technical deficiency, other "warnings"), noncompliance and therapeutic management after CGMS.

\section{Statistics}

The data were collected and analyzed by the Minitab software, by the t test, chi-square test and regression test. A $p$ value $<0.05$ was regarded as significant. In cases of continuous variables without normal distribution, the data were expressed as median (M) and $\mathrm{IQ}_{25-75 \%}$ and compared by the Mann Whitney test. The variables expressed by percentage were analyzed by median and $\mathrm{IQ}_{25-75 \%}$.

\section{Results}

The number of glucose readings during CGMS showed a median of 780, $\mathrm{Q}_{1}=715.2$ and $\mathrm{Q}_{3}=840.7$ ( $\left.\mathrm{NR}>680\right)$, with a significant value in $87.5 \%$ of patients. The average number of hours per sensor was 71.4 hours/median of 70.25 hours. The correlation coefficient between SBGM and CGMS values was $0.86 \pm 0.21$ ( NR >0.79), with ideal values in $93.75 \%$ of the studied patients. With regard to the MAD, the median value was $12.6 \%$, with $\mathrm{Q}_{1}=11.1$ and $\mathrm{Q}_{3}=16.5$ (NR $<28 \%$ ), which was significant in $87.5 \%$ of patients. The main reason for the higher numbers of usable CGMS data were patient compliance, due to inclusion of minimum four capillary glycemia each day.

The mean capillary glucose values obtained by the CGMS sensor were $214.3 \pm 66.5 \mathrm{mg} / \mathrm{dl}$ vs. $207.6 \pm 54.6 \mathrm{mg} / \mathrm{dl}$, with statistical significance detected by Pearson's correlation $(p=0.001)$ (Figure 1$)$ and Mann-Whitney test $(W=151$, significant at 0.97).

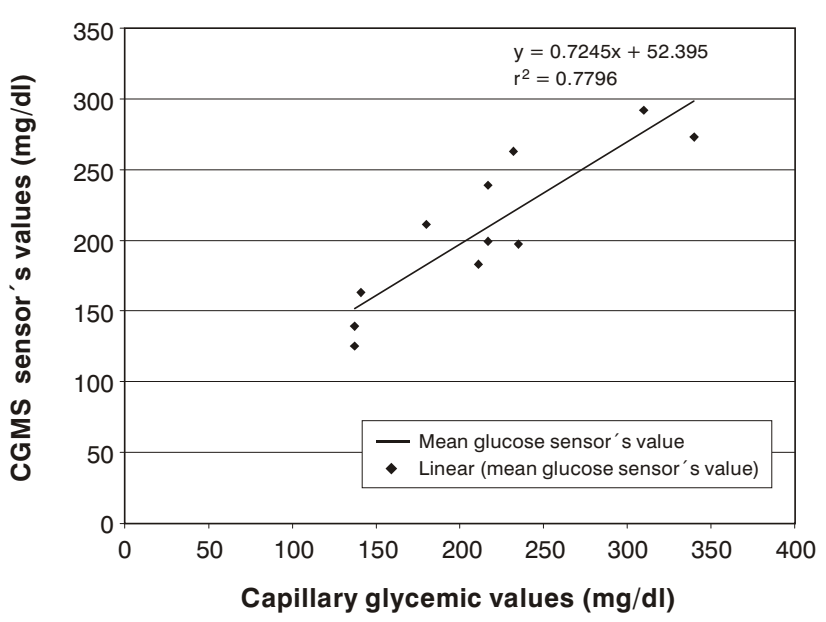

Figure 1 - Correlation of glucose values detected by the continuous glucose monitoring system (CGMS) sensor vs. fingerstick sampling values in pediatric type 1 diabetic patients $\left(r^{2}=0.77 ; p=0.001\right)$

As to glucose excursions, CGMS was more efficient compared to fingerstick CBG sampling, according to the Mann-Whitney test ( $W=74$, significant at 0.53 ). Postprandial hyperglycemia was identified in $60 \%$ of pediatric type 1 diabetic patients with a median of $157 \mathrm{mg} / \mathrm{dl} ; \mathrm{Q}_{1}=104 \mathrm{mg} / \mathrm{dl}$ and $\mathrm{Q}_{3}=246 \mathrm{mg} / \mathrm{dl}$ ( $\mathrm{NR}<140 \mathrm{mg} / \mathrm{dl}$ ). Nocturnal hypoglycemia was detected in $46.7 \%$ of these patients. During the CGMS ( 72 hours), the patients were in a state of hyperglycemia, hypoglycemia and normoglycemia during $M=59 \%\left(Q_{1}: 22.5, Q_{3}: 82.5\right) ; M=5 \%\left(Q_{1}: 1, Q_{3}: 8\right)$ and $M=40 \%\left(Q_{1}: 14.5, Q_{3}: 69.5\right)$, respectively.

The evaluation of $\mathrm{A} 1 \mathrm{c}$ levels in eight ( $50 \%)$ patients before CGMS and after 3 months showed statistical significance with decreased level of $\mathrm{A} 1 \mathrm{c}$ in this population (8.18 \pm 1.5 vs. $7.28 \pm 1.3 ; p=0.034)$.

No complications were observed in $93.7 \%$ of patients. Disconnection was the most common sign in this case $(12.5 \%)$. No trauma, local infection, allergy, bleeding or other symptoms were detected during CGMS in this study. Psychological aversion and technical deficiency were not observed in this population. All patients (100\%) fully completed the CGMS.

The therapeutic management of pediatric type 1 diabetic patients was changed in $100 \%$ of patients, including insulin dose adjust, change of insulin type, introduction of nutritional and psychological support and physical activity.

\section{Discussion}

This study is the first one that assesses the accuracy, utility and complications of CGMS in pediatric patients in Brazil. In the present study, all patients who used the CGMS showed some decline in $\mathrm{HbA} 1 \mathrm{c}$ levels after 3 months, as also described by Ludvigsson et al. ${ }^{15}$ According to these data, 
only $50 \%$ of control children (who had the same care and SBGM testing, but not the CGMS) showed a reduction in $\mathrm{HbA} 1 \mathrm{c}$ levels. After 3 months, the decrease in mean $\mathrm{HbA1C}$ levels for the CGMS group ranged from 8.18 to $7.28 \%$, similar to the findings of Ludvigsson et al. ${ }^{15}$

The CGMS involves the insertion of a subcutaneous sensor, which is easier for some patients compared with others. Three of the 12 adults chosen by Bode et al. did not participate, and one of the 12 children who initially volunteered to participate in this trial did not complete any sensors. These data show total adherence to the CGMS, with no interruption during the procedure.

These data showed that the CGMS was highly accurate compared to $C B G$, a finding that is consistent with the medical literature. ${ }^{8-12}$ Sachedina \& Pickup demonstrated the correlation between sensor and fingerstick values in 18 DM1 patients submitted to CGMS for 72 hours. The CGMS proved to be better than intensive CBG (eight times a day) at the detection of asymptomatic hypoglycemia and postprandial hyperglycemia, which is in agreement with our data. ${ }^{16}$ We verified a correlation coefficient of 0.86 , with a significant value in more than $90 \%$ of patients, corroborated by Djakoure-Platonoff et al. ${ }^{17}$ They obtained a correlation coefficient of 0.92 , with a significant value in $93 \%$ of cases and a MAD of $25 \%$. This group considered CGMS for 72 hours as highly accurate and as the gold standard for the determination of the glucose profile in diabetic individuals. Guerci et al. reported the accuracy, performance, and reproducibility of the CGMS in 18 type 1 diabetic patients submitted to CGMS for 72 hours, with mean duration of CGMS recording of $63 \pm 12$ hours, 692 pairs of data for glucose meter readings and CGMS, correlation coefficient ranging from 0.87 to 0.92 (NR > 0.79) and the mean absolute error ranging from 12.8 to $15.7 \%(N R<28 \%)$ as the most frequent observations. ${ }^{18}$

In pediatric patients, the CGMS showed to be a very safe method and an important alternative to promoting the reduction of $\mathrm{A} 1 \mathrm{c}$ levels, therapeutic adjustment, education and motivation of patients. ${ }^{15}$ In the USA, 12 diabetic adolescents ( $\mathrm{A} 1 \mathrm{C}>8 \%$ ) were submitted to CGMS for 72 hours. The CGMS promoted detection of glucose excursions in all patients, postprandial hyperglycemia in 10/12 cases and nocturnal hypoglycemia in $30 \%$ of patients. After 2 months, they observed a significant decrease in A1c levels. ${ }^{19}$ These data were very similar to our findings in Brazilian children and adolescents with DM1.

About the efficacy of the CGMS sensor in detecting glucose excursions, our results corroborated those obtained in many other studies. ${ }^{20-23}$ These data showed that the CGMS is very useful to detect postprandial hyperglycemia. Recent data of 91 DM1 patients estimate that the accuracy of the CGMS sensor is more effective in elevated glucose levels than in hypoglycemic state. ${ }^{20}$

The efficacy of the CGMS in detecting hypoglycemia is not well established in the medical literature. ${ }^{13-15}$ Boland et al. detected nocturnal hypoglycemia in $70 \%$ of 56 type 1 diabetic children submitted to CGMS for 72 hours and considered this method a gold standard for the management of hypoglycemia in the pediatric population submitted only to SMBG. ${ }^{23}$ Guerci et al. observed low sensitivity of the CGMS sensor in detecting hypoglycemic levels (33\%) in diabetic patients. ${ }^{18}$ According to Mcgowan et al., the CGMS sensor presented low efficacy in detecting hypoglycemia in adolescents with DM1. The correlation coefficient during hypoglycemic episodes showed only 0.76 (NR $>0.79$ ) of concordance and has to be analyzed with caution. ${ }^{22}$

Chico et al. ${ }^{24}$ reported that the CGMS was useful in detecting unrecognized hypoglycemia and in improving metabolic control in 70 diabetic patients submitted to CGMS for 72 hours. The CGMS detected unrecognized hypoglycemia in $62.5 \%$ of type 1 diabetic patients and in $46.6 \%$ of type 2 diabetic patients, and a remarkable decrease in A1c levels was observed after 3 months in both types of patients, similarly to these data. These findings suggest that the CGMS is useful in detecting unrecognized hypoglycemia in diabetic patients and in improving metabolic control. However, Kovatchev et al. revealed that the accuracy of sensor readings was lower in hypoglycemia $(73.5 \%)$ versus euglycemia (99\%) and hyperglycemia (95.4\%), and failure to detect hypoglycemia was the most common error during the test. ${ }^{13}$

In a recent study of nocturnal hypoglycemia with 50 children with diabetes who were hospitalized overnight, $47 \%$ had a blood glucose level below $60 \mathrm{mg} / \mathrm{dl}$ ( $<3.3 \mathrm{mmol} / \mathrm{l}$ ) during the night (using hourly blood glucose determinations). ${ }^{25}$ The authors found that $49 \%$ of the cases were asymptomatic. The data obtained by Ludvigsson et al. suggest that the incidence of asymptomatic episodes amounts to approximately $85 \%$ (17 of 20 ).

No complications were observed in $96.7 \%$ of patients. No trauma, local infection or bleeding was detected. The insulin regimen was adjusted in $100 \%$ of patients. In Guerci et al., disconnection was the most common problem detected during the CGMS, without any side effects reported at the site of sensor implantation. ${ }^{18}$ In this study, disconnection was the most common problem detected during the CGMS, in agreement with Guerci et al. Ludvigsson et al. observed some failure to enter at least four SBGM values during the day and that usable data were not obtained. ${ }^{15}$ According to these data, all the children had at least four fingerstick values entered, resulting in high accuracy of CGMS values.

\section{Conclusions}

This study suggests that the CGMS is a very good method for the detection of glucose excursion, postprandial hyperglycemia, and for the improvement of metabolic changes in therapeutics with significant impact on A1c levels of pediatric type 1 diabetic patients. The CGMS is a very safe, well-tolerated and highly accurate method, with a low complication rate. The use of this method should be actively encouraged by physicians and patients. The efficacy of the CGMS in detecting hypoglycemia is still unclear in the medical literature. 


\section{References}

1. Ferraz DP, Maia FF, Araújo LR. Glicemia capilar em ponta do dedo versus lóbulo de orelha: estudo comparativo dos valores resultantes e preferências dos pacientes. Arq Bras Endocrinol Metab. 2004;48:389-93.

2. Glasgow RE, Ruggiero L, Eakin EG. Quality of life and associated characteristics in a large national sample of adults with diabetes. Diabetes Care. 1997;20:562-7.

3. The DCCT Research Group. Effect of intensive diabetes treatment on the development and progression of long-term complications in adolescents with insulin-dependent diabetes mellitus: Diabetes Control and Complications Trial. J Pediatr. 1994;125:177-88.

4. The Diabetes Control and Complications Trial Research Group (DCCT) The effect of intensive treatment of diabetes on the development and progression of long term complications in insulin-dependent diabetes mellitus. N Engl J Med. 1993;329: 977-86.

5. Maia FF, Araújo LR. Aspectos psicológicos e controle glicêmico de um grupo de pacientes com diabetes mellitus tipo 1 de Minas Gerais. Arq Bras Endocrinol Metab. 2004;48:261-6.

6. The Diabetes Research in Children Network (DirecNet) Study Group: Accuracy of the GlucoWatch G2 Biographer and the Continuous Glucose Monitoring System during hypoglycemia. Experience of the Diabetes Research in Children Network (DirecNet). Diabetes Care. 2004;27:722-6.

7. The DCCT Research Group. Epidemiology of severe hypoglycemia in the Diabetes Control and Complications Trial. Am J Med. 1991;90:450-9.

8. Anderson RJ, Freedland KE, Clouse RE, Iustman PJ. The prevalence of comorbid depression in adults with diabetes: a meta-analysis. Diabetes Care. 2001;24:1069-78.

9. Kaufman FR. Role of continuous glucose monitoring in pediatric patients. Diabetes Technol Ther. 2000;2:S49-52.

10. Boland EA, Tamborlane VW. Continuous glucose monitoring in youth with type 2 diabetes: overcoming barriers to successful treatment. Diabetes Technol Ther. 2000;2:S53-9.

11. Caduff A, Hirt E, Feldman Y, Ali Z, Heinemann L. First human experiments with a non-invasive, non-optical continuous glucose monitoring system. Biosens Bioelecton. 2003;19:209-17.

12. Aussedat B, Dupire-Angel M, Gifford R, Klein JC, Wilson JS, Reach G. Interstitial glucose concentration and glycemia: implications for continuous subcutaneous glucose monitoring. Am J Physiol Endocrinol Metab. 2000;278:E716-28.

13. Kovatchev BP, Gonder-Frederick LA, Cox DJ, Clarke WL. Evaluating the accuracy of continuous glucose-monitoring sensors. Diabetes Care. 2004;27:1922-8.

14. McGowan K, Tomas W, Moran A. Spurious reporting of nocturnal hypoglycemia by CGMS in patients with tightly controlled diabetes. Diabetes Care. 2002;25:1499-1503.

15. Ludvigsson J, Hanas R. Continuous subcutaneous glucose monitoring improved metabolic control in pediatric patients with type 1 diabetes: a controlled crossover study. Pediatrics. 2003; 111:933-8.
16. Sachedina N, Pickup JC. Performance assessment of the Medtronic-Minimed Continuous Glucose Monitoring System and its use for measurement of glycaemic control in Type 1 diabetic subjects. Diabet Metab. 2003;20:1012-15.

17. Djakoure-Platonoff C, Radermercker R, Reach G, Slama G, Selam JI. Accuracy of the continuous glucose monitoring system in inpatient and outpatient conditions. Diabetes Metab. 2003;29:159-62.

18. Guerci B, Floriot $M$, Bohme $P$, Durain D, Benichou $M$, Jellimann $S$, et al. Clinical performance of CGMS in type 1 diabetic patients treated by continuous subcutaneous insulin infusion using insulin analogs. Diabetes Care. 2003;26:582-9.

19. Schaepelynck-Belicar P, Bague P, Simonin G, Lassmann-Vague V. Improved metabolic control in diabetic adolescents using the continuous glucose monitoring system (CGMS). Diabet Metab. 2003;29:608-12.

20. The Accuracy of the CGMS in children with type 1 diabetes: results of the Diabetes Research in Children Network (DirecNet). Diabetes Technol Ther. 2003;5:781-9.

21. Steil GM, Rebrin K, Mastrototaro J, Bernaba B, Saad MF. Determination of plasma glucose during rapid glucose excursions with a subcutaneous glucose sensor. Diabetes Technol Ther. 2003;5:27-31.

22. Metzger M, Leibowitz G, Waistein J, Glaser B, Raz I. Reproductibility of glucose measurements using the glucose sensor. Diabetes Care. 2002;25:1185-91.

23. Boland $E$, Monsod $T$, Delucia $M$, Brandt CA, Fernando $S$ Tamborlane VW. Limitations of conventional methods of selfmonitoring of blood glucose: lessons learned from 3 days of continuous glucose sensing in pediatric patients with type 1 diabetes. Diabetes Care. 2001;24:1858-62.

24. Chico $A$, Vidal-Rios $P$, Subira $M$, Novials $A$. The continuous glucose monitoring system is useful for detecting unrecognized hypoglycemias in patients with type 1 and type 2 diabetes but is not better than frequent capillary glucose measurements for improving metabolic control. Diabetes Care. 2003;26:1153-7.

25. Boyne M, Silver D, Kaplan J, Saudek C. Timing of changes in interstitial and blood glucose measured with a continuous subcutaneous glucose sensor. Diabetes Care. 2000;49 (Suppl 1):398.

Correspondence:

Frederico Fernandes Ribeiro Maia

Rua Nunes Vieira, 299/702, Santo Antônio

CEP 30350-120 - Belo Horizonte, MG

Tel.: (31) 3296.3345

Fax: (31) 3283.9772

E-mail: fredfrm@hotmail.com; frederico@diabetes.med.br 